\title{
The Research and Design of Intelligent Card Free Bus Software
}

\author{
Jiangtao Dang ${ }^{1,}$, Bo Fu ${ }^{1, b}$, Fei Mi ${ }^{1, c}$, Xin Quan ${ }^{1, d}$ and Yao Zhang ${ }^{1, e}$ \\ ${ }^{1}$ Faculty of Science, Xi'an Technological University, Xi'an Shaanxi, 710032 \\ a1243330234@qq.com, ${ }^{\mathrm{b}} 779523483 @ q q . c o m,{ }^{\mathrm{c}} 1124725762 @ q q . c o m,{ }^{\mathrm{d}} 87122 \mathrm{~s} 6078 @ q q . c o m$, \\ 1002937266@qq.com
}

\section{Keywords: NFC; No card bus; Software design}

\begin{abstract}
The bus process forget to take public transportation card lead to credit card by bus, the need to specify recharge recharge outlets is not convenient and the card balance inquiries inconvenient. In this paper, the design and the one based on near-field communication (NFC) no card bus software, using Android Studio software tools to realize the mobile terminal user registration, user log in, user information query, recharge and other functions can to take the bus to use mobile phone card, to a great extent solve the bus encountered some forget take public transportation card, embarrassing not convenient problem. The study has a certain value of application and popularization.
\end{abstract}

\section{Introduction}

Along with the technical progress, people on the food requirements more and more high, previously only required to solve the problem, and now how to efficiently completed. To take the bus, before people the main means of payment for two kinds, one kind is the cash coin, another kind is brush bus card. Have to say, the bus card for people to take the bus to bring great convenience, people do not need for change, only to take out card to brush a can, and the speed is quite fast. But if forget to take public transportation card go by bus or bus card balance of less than will encounter no credit card bus embarrassing situation, and people often will bring the necessary communication tool of mobile phone Go out, therefore, if developed with no public transportation card and only uses the phone card to take the bus, to the bus card mobile phone account recharge function mobile app software will solve the above problems, greatly convenient for people to travel. Therefore, this paper in view of the above problems, the phone bus card software research and design, this paper has a certain value of application and popularization.

\section{System Requirements}

In recent years, the use of mobile phones for contact less payment way due to its simple operation, transaction quickly, has gradually become a way of realization of the mainstream of the mobile electronic business. In the mobile payment business, the mobile terminal is responsible for direct interaction with the user, business presentation and use of key link.

In travel, the need to achieve stable proximity mobile interactive function, route recommendation function; in the management of user information and need to realize the function of user registration, user $\log$ in, online recharge function, balance inquiry function.

Near-field communication (NFC, near field communication technology is and is widely used in recent years a new technology, this technology is widely used in electronic payment, identification and information transfer for various applications in the field, thus promote telecommunications, banking, transportation and other fields into a step fusion, bring convenience to people's life. The technique can realize these functions. Thus, and extend the carrier selection problem.

Mobile communication terminal is, we usually say that the phone, with a unique advantage to become the carrier of NFC business users, mainly reflected in the following aspects: first, under the background of modern society, the vast majority of people have cell phones, the NFC user end module into a mobile phone will not increase additional carrying device; second, the phone is wireless communication terminal, NFC is a kind of wireless communication, NFC into a mobile 
phone, that can be shared some apparatus and device; third, mobile phone user identification module, in the mobile communication provides authentication, billing and other functions; in addition, the phone comes with the application management module, Can download the software, install, uninstall and other functions, and these functions, can meet some of the requirements of NFC. Therefore, this paper chooses NFC based mobile phone bus software research and design work.

\section{System Design}

In the software design phase, according to the requirements of the results of the analysis of the software system structure design, as shown in Fig. 1, mainly including the log in, registration, NFC, recharge and information inquiries:

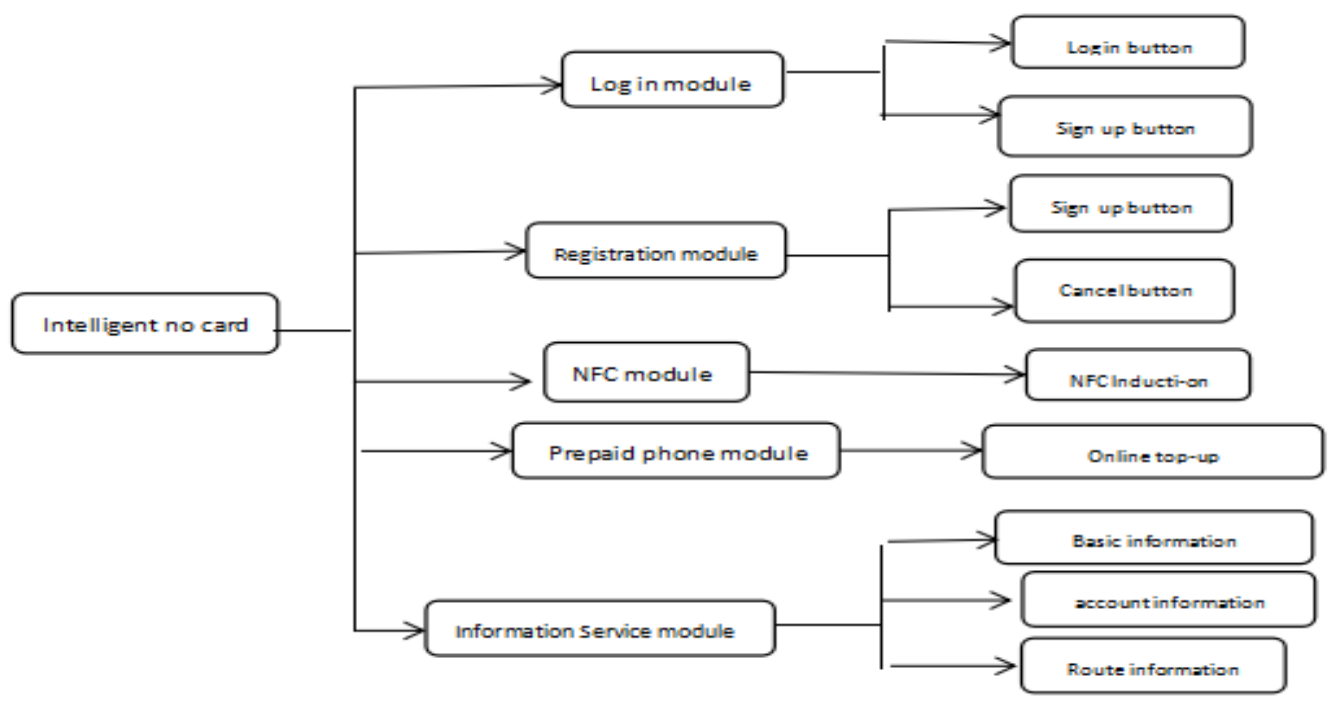

Figure 1. System hierarchy diagram

(1)Log in section has two buttons, button on the log in and registration button. For the first time using software users register button, jump to register interface register, after registration to jump back to $\log$ in, registered users can directly fill in the account number and password to log in.

(2)Registered to the user registration information to fill out, including name, sex, contact way, identity card number, completed can click the register button real name registration system, you can also choose to cancel the registration option.

(3) NFC part is the part of the technical support, responsible for the induction card, and the bus sensors to achieve information interaction.

(4) Recharge part is to achieve the user online recharge function.

(5) Information search part includes basic information, account information inquiry and route information query. Basic information is registered users to fill in the information, account information query, including the account balance and recharge details and other information query, route information query is the ride number in length, distance analysis and recommended to the user the appropriate route query.

By the results of the above system structure design can be seen, the software is set route, credit card, recharge and other functions as one of the bus software, can achieve a machine through, a great place for people to travel.

\section{Software and Hardware Environment and Main Interface Design}

Software and Hardware Environment. The software design and research of the software used in the work environment is mainly Windows 7 (64 bit) system, studio Android software; hardware is a mobile phone with NFC function, NFC card reader and so on. 
In the software stored in the NFC tags, and in the bus supporting NFC reader hardware environment, in the use of mobile phones by bus, using a mobile phone near the bus NFC reader, through the identification of the filter to the label, then you can exchange information, to achieve the phone card to take public transport function. The technology is gradually mature, in the speed, stability and sensitivity, which can achieve the desired requirements.

Main Interface Design. Bus intelligent card app software interface design as shown in Fig. 2 and figure software identification for "bus" pattern is the design of the intelligent public transportation card software. By double clicking on the icon, you can enter the software user interface, including the log in, registration card, recharge and other functions, according to demand by clicking on the different functions of the operation interface.

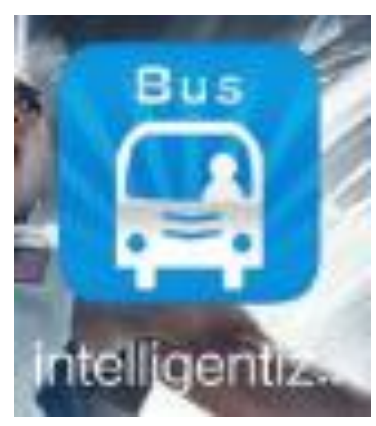

Figure 2. Intelligent bus software icon

First, if you want to use the software, must first log in to use. Therefore, it is necessary to click software icon open the software, enter the log in interface, as shown in Fig. 3(a), if the existing account and password to $\log$ in directly, or need to register after logging in again. Click the "register" jump to register interface, as shown in Fig. 3(b), click log in to jump to the internal function of the interface, as shown in Fig. 4(a).

Jump to the registration page, fill in the user name information, including name, gender, identity card number, contact, after the completion of the click the register button to register, as shown in Fig. 3(b) can also be click the Cancel button to cancel the registration.

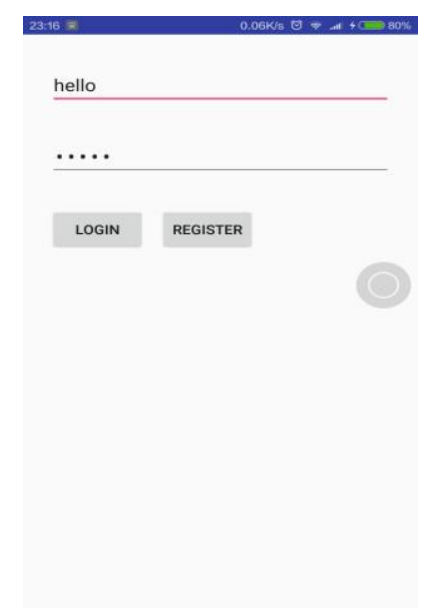

(a) Log in interface

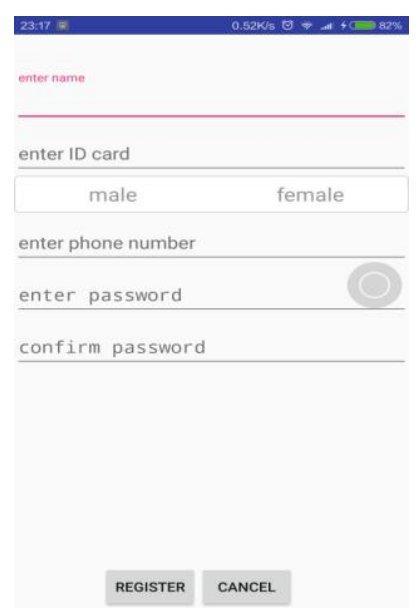

(b) Registration interface

Figure 3. Log in and Registration interface

After landing successfully, then jump to the following internal functional interface, as shown in Fig. 4(a), this interface is mainly displayed NFC, recharge, inquiries, etc. Fig. 4(b), Fig. 4(c) shows. 


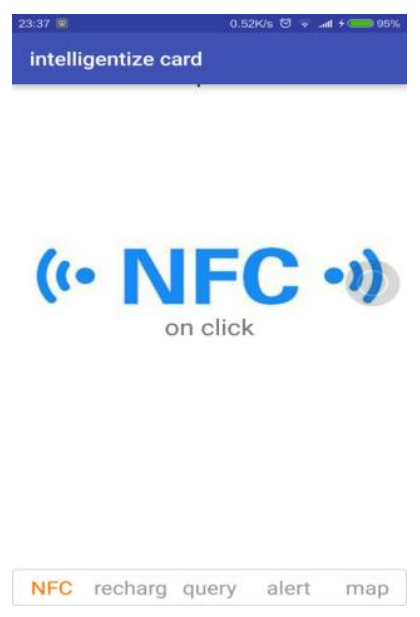

(a) Brush bus card payment interface

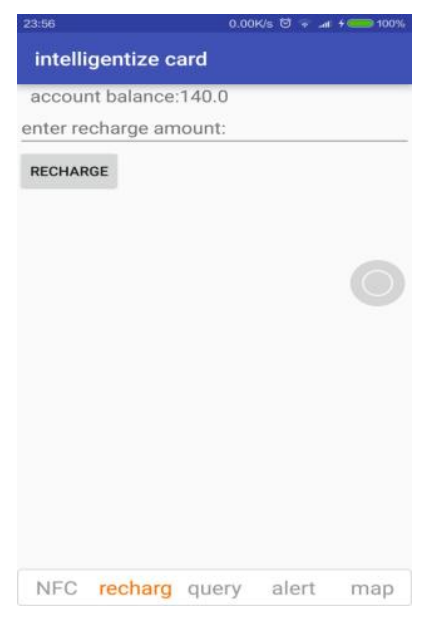

(b) Recharge function interface diagram

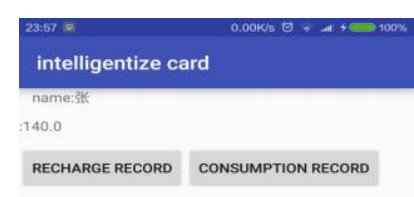

NFC recharg query alert map

(c) Virtual data recharge history interface

Figure 4. The main function Interface Design.

Result Analysis. Based on the requirement analysis and design of software bus intelligent card, from the point of view of system structure design results, including the registration, log in, credit card, recharge, query and other mainly "smart card passenger bus function, from the division of the function module is basically rational, the realization of the no cards take public transportation, has many advantages. The software has the benefits of basically has a few:

From the carry it and traditional bus card need to carry; and the design of the intelligent no card only need to download to the phone and through the software can register for a new bus card account software bus ride, and the mobile phone is always belongings in a, as long as the user carrying mobile phones to go out without the need for in addition to carry a bus card, the cards take the bus.

From the perspective of recharge, want to traditional bus recharge card must be assigned to recharge, and the design of the software can realize online recharge and account balance inquiry, great convenience to the user of public transportation card recharge.

From the technical side, NFC mobile phone technology is more and more mature and popular, is the trend of social development and trends, in line with the basic needs of the majority of people.

\section{Summary}

In this paper, we study and design a smart card bus system, the smart card by bus by using NFC technology to realize short distance wireless communication card "by bus, from the aspects of function, meet the people's needs, a great convenience to people by bus payment process, you can use the software to operate online recharge; from the background level, the popularity of mobile NFC for the promotion of the software well foundation work; from the technical level, NFC technology is more and more mature, more and more perfect, more and more convenient to meet the people's needs. Therefore, based on NFC technology of intelligent cards take the bus software completely Has certain application and popularization value.

\section{Acknowledgements}

The author(s) disclosed receipt of the following financial support for the research, authorship, and/ or publication of this article: The research is supported by the grant from the National College Students Innovation Training Program (grant no. 201510702019).

\section{References}

[1] Lin Li, requirements and scheme of NFC mobile phones, Telecommunications Technology, 
2011.2.

[2] Fan Wu, NFC mobile payment system, credit card in China, 2008.4.

[3] Kai Lu, Xudong Meng, the research and application of NFC mobile communication terminal, modern telecommunication technology, 2008.11, 11.

[4] Ruibin Wang, Research and implementation of bus based on NFC payment systems, Fujian computer, 2014.

[5] Jian Meng, Shaofen Chen, Based on the research and application of the mobile payment NFC E - Business Journal, 2008.8.

[6] E.M. Rogers, Diffusion of Innovations, fifthed, Free Press, New York, 2003.

[7] R. Safeena, N. Hundewale, A. Kamani, Customer's adoption of mobile-commerce: a study on emerging economy, Int. J. e-Educ. e-Bus. e-Manag. e-Learn. 1 (2011) 228e233.

[8] Card Technology Today, Taiwanese survey reveals mobile payment preference over cards, Card. Technol. Today 19(7/2007)16.

[9] Wang Yu-wei, Zhanga Hui. Research on mobile NFC application [J]. China Radio, 2007(6): 3-8.

[10] Yao Gang. NFC technology becomes popular via android platform [J]. EDN China, 2011(3): 69-70. 